\title{
RECOMMENDATION TO REPLACE PVC DISPOSABLE SHOE COVER WITH ALTERNATIVE MATERIALS (U)
}

by A. E. Slaughter

Westinghouse Savannah River Company Savannah River Site

Aiken, South Carolina 29808

Other Authors:

W. N. Rankin

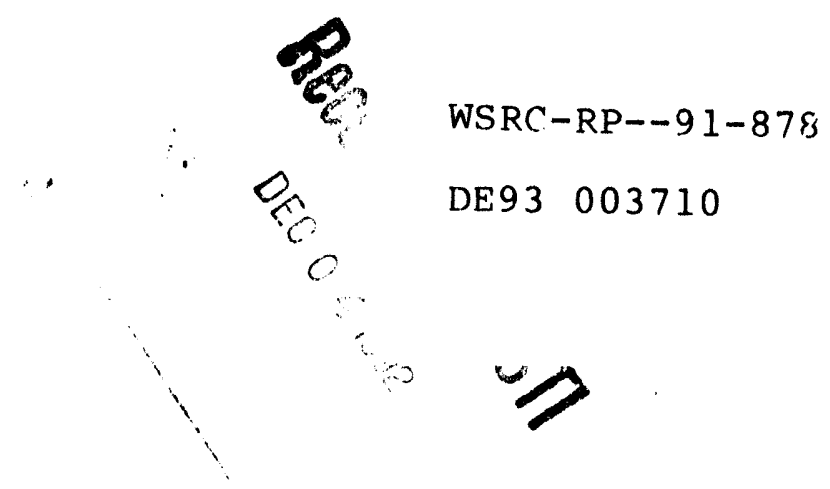

This paper was prepared in connection with work done under Contract No. DE-AC09-89SR18035 with the U.S. Department of Energy. By acceptance of this paper, the publisher and/or recipient acknowledges the U.S. Government's right to retain a nonexclusive, royalty-free license in and to any copyright covering this paper, along with the right to reproduce and to authorize others to reproduce all or part of the copyrighted paper.

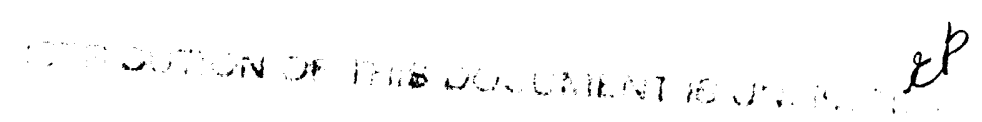




\section{DISCLAIMER}

This report was prepared as an account of work sponsored by an agency of the United States Government. Neither the United States Government nor any agency thereof, nor any of their employees, makes any warranty, express or implied, or assumes any legal liability or responsibility for the accuracy, completeness, or usefulness of any information, apparatus, product, or process disclosed, or represents that its use would not infringe privately owned rights. Reference herein to any specific commercial product, process, or service by trade name, trademark, manufacturer, or otherwise does not necessarily constitute or imply its endorsement, recommendation, or favoring by the United States Government or any agency thereof. The views and opinions of authors expressed herein do not necessarily state or reflect those of the United States Government or any agency thereof.

This report has been reproduced directly from the best available copy.

Available to DOE and DOE contractors from the Office of Scientific and Technical Information, P.O. Box 62, Oak Ridge, TN 37831; prices available from (615) 576-8401, FTS 626-8401.

Available to the public from the National Technical Information Service, U.S. Department of Commerce, 5285 Port Royal Rd., Springfield, VA 22161. 
WESTINGHOUSE SAVANNAH RIVER COMPANY SAVANNAH RIVER LABORATORY DIVISION

WSRC-RP $-91-878$

KEY WORDS: WASTE MINIMIZATION

JANUARY 17,1992

TO: W. E. STEVENS, 773-43A

FROM: $\quad$ A. E. SLAUGHTER, 773-43A

W. N. RANKIN, 773-A wMlankin.

RECOMMENDATION TO RERLACE PVC DISPOSABLE SHOE COVER WITH ALTERNATIVE MATERIALS (U)

\section{SUMMARY}

An alternative for disposable shoe covers presently fabricated from PVC (polyvinyl chloride) was investigated to minimize disposal costs. Plans are to incinerate these items for disposal. The exhaust from the incineration of PVC must be processed through a sodium hydroxide scrubber to remove the chlorides. A substantial cost savings ( $\$ 700 \mathrm{~K} / \mathrm{yr})$ would be expected from replacing these supplies with similar items fabricated from a material that contains no chlorides.

Out of the seventeen shoe covers evaluated, we recommend the Rich Industry's polyethylene shoe cover. These shoe covers are both incinerable and disposable. They have a relatively high coefficient of friction and puncture resistance. The total estimated cost savings by switching to Rich Industries polyethylene shoe cover is $\$ 700 \mathrm{~K} / \mathrm{yr}$. In addition a reduction of $200,000 \mathrm{gal} / \mathrm{yr}$ of CIF Blowdown would be realized.

Plans are to continue to investigate non-PVC alternatives. Paul D. Wicker, IH\&S plans to conduct a large scale Plant evaluation with the Rich Industries polyethylene shoe covers. If the results of this evaluation are satisfactory, wicker plans to change the sitewide shoe cover specification from PVC to white polyethylene.

SRL also plans to investigate alternatives to PVC bags. 


\section{INTRODUCTION}

A cost benefit analysis was performed on sample shoe covers obtained from twelve manufacturers. The total nuinber of samples evaluated was seventeen (some of the manufacturers sent more thar one type of shoe cover sample). Although this investigation was limited to disposable shoe covers, some of the shoe cover samples sent by the manufacturers were not disposable but reusable. (Information collected on these shoe covers is included in this report to document for possible future need). Information on all of the shoe covers available from the manufacturers was collected. This information was arranged in spreadsheet form so that a comparison could be made of the different alternatives. Some properties of the shoe covers were measured at SRL. For example, the coefficient of friction was determined between the alternative shoe covers and Kraft paper. Puncture resistance was also measured. To test for wear resistance, a durability walking test was conducted. We appreciate the support provided by B.G. Creech, Safety, and P. D. Wicker, Health Protection in this effort.

\section{DISCUSSION}

1. Estimated Cost Savings - In his report "CIF Blowdown Characterization" (U) (IWT-STW-91-098), Dan Burns (IWT) estimates that the amount of waste generated from incineration of PVC waste is 369,000 gal/year. With an $80 \%$ reduction in chloride content, the waste to be disposed of drops to 151,000 gal/year. Steve Lorah estimates that at least $80 \%$ of the PVC waste is shoe cover waste.

According to Michelle Wells, it costs $\$ 9$ per gallon to dispose and treat 369,000 gallons of waste. The total disposal and treatment cost is $\$ 3.3 \mathrm{M}$. Likewise, it costs $\$ 15$ per galion to dispose and to treat 151,000 gallons of waste (generated by an $80 \%$ reduction of chlorides). The total treatment and disposal cost for 151,000 gallons is $\$ 2.3 \mathrm{M}$. Assuming $80 \%$ of the PVC for disposal is from shoe cover waste, the total savings by eliminating PVC shoe covers is $\$ 1 M$.

2. Manufacturers' Information Collected - Information from the different manufacturers was collected on each shoe cover sample and recorded on a spreadsheet (Table 1). Specific information included the following: style, material(s), cost, size availability, tensile strength, puncture resistance, tear resistance, thickness, length, height, weight, carton weight, wear resistance, elongation percentage, and miscellaneous information that appeared relevant. Some of the information was not available from a few of the manufacturers.

The shoe covers evaluated are listed below. 
a. FRHAM Safety Products, Inc. - Consisting of $90 \%$ natural rubber and $10 \%$ process acids, the sample is a yellow no-seam shoe cover that is constructed out of a single rubber sheet and equipped with a "non-skid" sole. It is of a "loafer" type and is incinerable, reusable, and waterproof. The shoe covers are $\$ 6.85$ a pair for $1-x l$ and $\$ 6.95$ a pair for $x s-s m, s m-m$, and $m-1$.

b. Island Poly - This seamless shoe cover is light blue and semi-transparent. It has an elastic band for securement and fits below the ankle. The disposable shoe cover is made out of polyethylene and is both waterproof and incinerable. The cost is $\$ 0.10$ per pair.

c. G/O Supply Company - Having an H-cut opening and no right or left distinctions, the shoe cover is yellow with a hot-sealed edge. There is an anti-skid grid on the sole. The shoe cover's material is polyethylene (with a skid-resistant sole), which is incinerable. It is also waterproof and disposable. The cost is $\$ 0.40$ a pair.

d. J.S.M. Protective, Inc. - This disposable shoe cover has an H-cut opening and a hot-sealed edge with no tread on the sole for skid-resistance. It is made of polyethylene and is both incinerable and waterproof. A pair of the shoe covers costs $\$ 0.20$ for $\mathrm{sm}, \$ 0.21$ for $\mathrm{m} / \mathrm{l}, \$ 0.22$ for 1 , and $\$ 0.23$ for $\mathrm{x \times l}$.

e. Mar-Mac Manufacturing Co., Incorporated - 740: This shoe cover, having an elastic band for securement around the ankle, is white and is manufactured out of all of the same material -DuPont TYVEK (polyethylene fibers). There are gathers around the elastic seam that run through the middle of the shoe cover. It is not waterproof but is incinerable and disposable (may be laundered). The cost per pair is $\$ 0.31 .740$ PB: This shoe cover is white with an elastic opening for securement around the ankle. It has a white vinyl plastic bottom that is sown to the upper part of the shoe cover. The sample is made out of DuPont TYVEK and vinyl plastic on the sole. Although it is incinerable and disposable (may be laundered), the shoe cover is not waterproof. A pair costs $\$ 0.53$. 740 SR: This shoe cover is white with an elastic band around the ankle for securement. The inside material of the shoe cover is a tan color; it helps in skid-resistance. The shoe cover has an elastic seam that runs through its middle with gathers around the elastic seam. The material of the sample is TYVEK FC, which enhances friction. It is incinerable and disposable (may be laundered) but not waterproof. The cost per pair is $\$ 0.36$.

f. Designs by Norvell, Inc. - a. The upper part of the shoe cover is yellow, and the sole is a grayish/white color. There is an elastic band for securement around the lower ankle level. The upper and lower portions of the shoe cover are connected by a series of stitched seams. The bottom is made of reinforced PVC, and the upper is made of 70 denier taffeta. The shoe cover is incinerable and reusable but not waterproof. The cost per pair i,j 
$\$ 2.60 . b$. The shoe cover is light yellow on top with a grayish/brown colored sole. Having an elastic band for an opening, the sample's upper and lower materials are connected by a series of stitched seams. It's upper material is made of the 200 denier (which is a 1 ounce coating of polyurethane), and the bottom consists of hypalon (which acts as a flame retardant and helps in skid-resistance). It is incinerable and reusable but not waterproof. The cost per pair for 1-75,000 pairs, 75,001-150,000 pairs, and 150,001-250,000 pairs is, respectively, $\$ 3.45, \$ 3.30$, and $\$ 3.20$ per pair.

g. Associated Bag Company - a. This is a dark blue shoe cover that fits over the ankle. It is sock-like with an elastic opening at the top and has a "non-slip" bottom. The material is terrycloth, which is porous and naturally not waterproof, but the material for the skid-resistant marks on the sole is unknown. These reusable shoe covers cannot be purchasid by random pairs; they must be bought in cases. One case is $\$ 50.50$ (24 pairs per case). In formation on whether or not the shoe covers are incinerable is not available. $b$. This reusable shoe cover has both a red and white checkered pattern. Shaped as a square with a loose opening, the shoe cover is pulled over the shoe to conceal most of it. Its material is a cotton stretch-knit, which is both porous and not waterproof. One pair costs $\$ 1.00$ (smallest amount able to sell is 250 pairs). Information about the incineration of the shoe covers is not available.

h. Euclid Garment Manufacturing - The shoe cover is white on top with a tan colored sole. Having an elastic band around the ankle for securement, the shoe cover also has "rear snap adjustment." The sample's upper material is made of Dacron taffeta, and the sole is made of reinforced-polyester vinyl. Costing $\$ 5.00$ a pair, the shoe cover is incinerable and reusable but not waterproof.

i. Lancs Industries Inc. - a. Having a smooth-ridged bottom, the shoe cover is all of the same material. It is ankle high, yellow, and has loose securement (no elastic band). The shoe cover's material is $100 \%$ Latex rubber. It is reusable, incinerable and waterproof. One pair costs $\$ 2.49$. b. The sole of the shoe cover has ridges with grains of cork in them. The shoe cover is yellow and composed of all of the same material; however, the material is thicker than a's material. This shoe cover's material is $100 \%$ Latex rubber (but has grains of cork on the sole as well). It is incinerable, waterproof, and reusable. The cost for one pair is $\$ 2.49$.

j. RAD-SAFE - This disposable shoe cover is yellow and made out of all the same material. Having no tread on the bottom for skid-resistance, the sample has an H-cut opening and a hot-sealed edge. The material of the shoe cover is polyurethane. It is incinerable and waterproof. The cost for a pair of shoe covers is $\$ 0.78$. 
k. FAB-Ohio - Having an embossed sole (diamond pattern), the shoe cover presently used at SRI is white with an H-cut opening. The shoe cover's material is PVC (polyvinyl chloride). Although it is not incinerable, it is waterproof and disposable. The cost for a pair of 12 inch shoe covers is $\$ 0.145$, and the cost for $a$ pair of 13 inch shoe covers is $\$ 0.148$.

1. Rich Industries - a. The other currently used shoe cover at SRL comes in either a yellow or green color. It has an $H$-cut opening with ar embossed sole (diamond pattern). The shoe cover's material is PVC (polyvinyl chloride). It is not incinerable; however, it is disposable and waterproof. A pair of the shoe covers costs $\$ 0.125, \$ 0.135, \$ .145$, and $\$ 0.170$ for the 13, 14, 15, and 16 inch shoe covers respectively. $b$. The shoe cover is yellow or white with a hot-sealed edge. It comes in an H-cut style and has a grid (diamond pattern) on the sole for skid-resistance. The material for the shoe cover is polyethylene. It is waterproof, disposable, and incinerable. The cost per pair for the 13, 14, 15, and 16 inch shoe covers is respectively $\$ 0.28$, $\$ 0.29, \$ 0.31$, and $\$ 0.33$.

3. On-Site Tests - Four on-site tests were performed (Table 2).

- Thickness Measurements - The first test involved micrometer readings. The micrometer is an instrument that measures the thickness of objects--in this case shoe cover samples. Thickness is expected to correlate with the individual shoe cover's wear resistance and puncture readings.

- Puncture Resistance Test - Using a force meter and two different puncture tips, each shoe cover sample was pressed separately on both tips (Figures 1, 2). The force meter measured the strength required to puncture the shoe covers. The diameter for the first tip was $250 \mathrm{mil}$ with an angle measure of $60^{\circ}$. The square point on top was $.013 \mathrm{mil}$ in diameter. The diameter for the second tip was also $250 \mathrm{mil}$ with an angle measure of $60^{\circ}$. This tip had a point.

To rank the shoe cover samples, the two blade point readings were averaged together. The highest average was 56.72 (Designs by Norvell: 200 Denier,light yellow). Each subsequent shoe cover average was divided by 56.72 and multiplied by 100 to calculate the percentage. The puncture resistance rankings, rounded to the nearest whole number, ranged from 1 to 100 .

- Coefficient of Friction Test - Using a force meter, an 18.5 lb stainless steel brick, and kraft paper, the coefficient of friction between the shoe cover material and the kraft paper was measured. Each shoe cover sample was fitted over the brick. The force meter was used to push the brick and shoe cover sample across the Kraft paper. The force required to move the brick was measured (Figure 3 ). 
To tabulate the coefficient of friction, the formula of $\mathrm{F} / \mathrm{N}$ was used (where the $F$ is the force measured by the force meter, and the $\mathrm{N}$ is the normal pressure which is the weight of the brick). The highest coefficient of friction reading was 0.76 (RAD-Safe). For ranking purposes each shoe cover's coefficient of friction reading was divided by 0.76 and then multiplied by 100 to get the percentage. The coefficient of friction rankings, rounded to the nearest whole number, ranged from 28 to 100.

- Durability Walking Test - Two colleagues, weighing around 200 lbs., walked in leather-sole shoes wearing the shoe cover samples. They walked 1.5 miles in the Piney woods Trail in front of 703-A (Figure 4). The trail floor is constructed out of "Eines" gravel which is smaller than "Pea" gravel (Figure 5).

After each walk, the descriptions of each shoe cover were recorded in a journal. The shoe covers were rated on a scale from 1 to 17 with 1 being the least durable and 17 being the most durable (Table 3).

\section{INTERPRETATION OF DATA}

A "figure of merit" was tabulated by adding together the coefficient of friction and puncture resistance rankings (Table 2). The "figure of merit" number reveals how well a particular shoe cover sample's coefficient of friction and puncture resistance rankings compete with the other shoe cover samples' rankings.

\section{ACCEPTANCE CRITERIA}

To be recommended, the shoe cover had to meet certain requirements. It had to be waterproof, disposable vs. reusable, incinerable (non PVC), durable, cost effective, and highly ranked within the "figure of merit" scale.

\section{RECOMMENDATION}

Out of the disposable shoe covers evaluated, the RAD-SAFE polyurethane shoe cover had the highest ranking for the coefficient of friction and the highest "figure of merit." The major problem with the shoe cover is the pricing. The total amount of shoe cover pairs worn on the site for twelve months $(1 / 89-1 / 90)$ is $2.0 \mathrm{M}$. With each pair of shoe covers costing $\$ 0.74$, the cost for buying $2.0 \mathrm{M}$ pairs is about $\$ 1.5 \mathrm{M}$. The purchasing price for the currently used PVC shoe cover (at $\$ 0.15 /$ pair for the 15 inch shoe cover) is $\$ 300 \mathrm{~K}$. Assuming a $\$ 1 \mathrm{M}$ savings in treatment and disposal costs, the RAD-SAFE polyurethane shoe covers would be a net cost increase of $\$ 200 \mathrm{~K} /$ year.

We recommend switching to the polyethylene shoe cover from Rich Industries. The products of combustion of the Rich Industries polyethylene shoe covers $\left(\mathrm{CO}_{2}, \mathrm{H}_{2} \mathrm{O}\right.$, and $\left.\mathrm{SiO}_{2}\right)$ were approved by the 
CIF Blowdown Task Team. The yellow shoe covers were used in our tests. Jane Bibler pointed out that there may be a problem with the dye used to color the material yellow. Investigation revealed that the dye in the yellow shoe covers contains small amounts of chromium and lead which would be undesirable in the CIF Blowdown. We are therefore recommending the white shoe covers, which do not contain these undesirable elements. These shoe covers are both disposable and incinerable. In comparison to the shoe cover that we presently use, these polyethylene shoe covers are higher in their elongation percentage ( $425 \%$ more), in their coefficient of friction ( 0.21 more), in their tear resistance $(4,256$ p.s.i. more), and in their "figure of merit" (23 points higher).

Although the polyethylene shoe cover fared well in the Durability Walking Test, it received a mark of 8 . The FRHAM Safety Products, Inc. shoe cover received a 17--most durable. The Mar-Mac Manufacturing Co. shoe cover (740 SR: tan inside cover) received a 1--least durable. The PVC shoe covers (yellow and white) currently used at SRL received a mark of 11. The main differences between the rankings of the PVC shoe cover currently employed and the polyethylene shoe cover from Rich Industries is that the polyethylene shoe cover's sole is more worn down and stretched in comparison to the sole of the PVC shoe cover, and there are more puncture marks in the polyethylene shoe cover.

The probable cause for the polyethylene shoe cover's mark of only an 8 has to do with the thickness of the sole of the shoe cover. This particular sample from Rich Industries has a sole thickness of $5.9 \mathrm{mil}$. Upon request, these shoe covers can be produced with 8 or 9 mil soles. In fact, the pricing we received from Rich Industries is for a thicker mil.

The purchasing price for $2.0 \mathrm{M}$ polyethylene shoe cover pairs from Rich Industries (at $\$ 0.31 /$ pair for the 15 inch shoe cover) is estimated to be $\$ 620 \mathrm{~K}$. The purchasing price for the currently used PVC shoe covers is $\$ 300 \mathrm{~K}$ (at $\$ 0.15 / \mathrm{pair}$ for the 15 inch shoe cover). Assuming a $\$ 1.0 \mathrm{M} / \mathrm{yr}$ savings in treatment and disposal costs, The Rich Industries polyethylene shoe covers would be a net cost savings of $\$ 700 \mathrm{~K} / \mathrm{yr}$.

\section{PATH FORWARD}

- Paul D. Wicker, IH\&S plans to conduct a large scale plant evaluation with the Rich Industries polyethylene shoe covers. If the results of this evaluation are satisfactory, Wicker plans to change the shoe cover specification from PVC to polyethylene.

- SRL plans to investigate alternatives to PVC bags. 


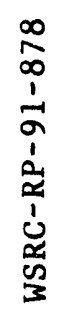

\begin{tabular}{|c|c|c|c|c|c|c|c|c|c|c|c|c|c|c|c|}
\hline$\frac{0}{4}$ & $\begin{array}{l}8 \\
80 \\
0\end{array}$ & : & & $:$ & $: 0$ & $\mid \begin{array}{l}3 \\
0 \\
2 \\
2\end{array}$ & $\mid$\begin{tabular}{l|}
8 \\
0 \\
0 \\
0 \\
0 \\
0 \\
2
\end{tabular} & & 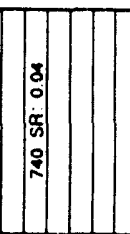 & $|\mathbb{a}|$ & $\begin{array}{l}\approx \\
0\end{array}$ & & & & \\
\hline$=0$ & 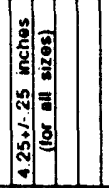 & $\frac{8}{8}$ & & 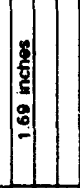 & 言 & $\mid \begin{array}{l}0 \\
\vdots \\
\vdots \\
\vdots \\
0 \\
\vdots \\
\vdots\end{array}$ & : & & $\mid \begin{array}{c}0 \\
0 \\
0 \\
0 \\
0 \\
0 \\
0 \\
0 \\
0 \\
0\end{array}$ & 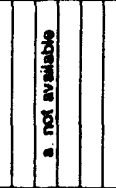 & 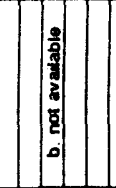 & & & & \\
\hline 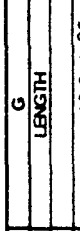 & $\begin{array}{ll}n \\
0 \\
0 \\
0 \\
0 \\
0 \\
0 \\
0 \\
0 \\
0\end{array}$ & $\begin{array}{l}5 \\
0 \\
0 \\
0\end{array}$ & & $\begin{array}{l}0 \\
0 \\
0 \\
0 \\
0 \\
0 \\
0\end{array}$ & 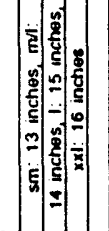 & : & 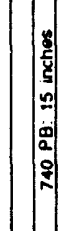 & & 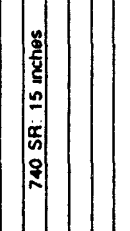 & : & 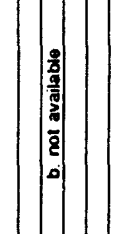 & & & & \\
\hline 4 & 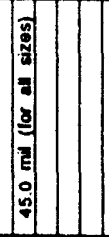 & 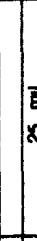 & & 这意 & $\overline{\overline{\bar{B}}}$ & 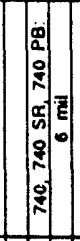 & & & 011 & 国国 & 圈目 & & . & & 㝵 \\
\hline
\end{tabular}

焉

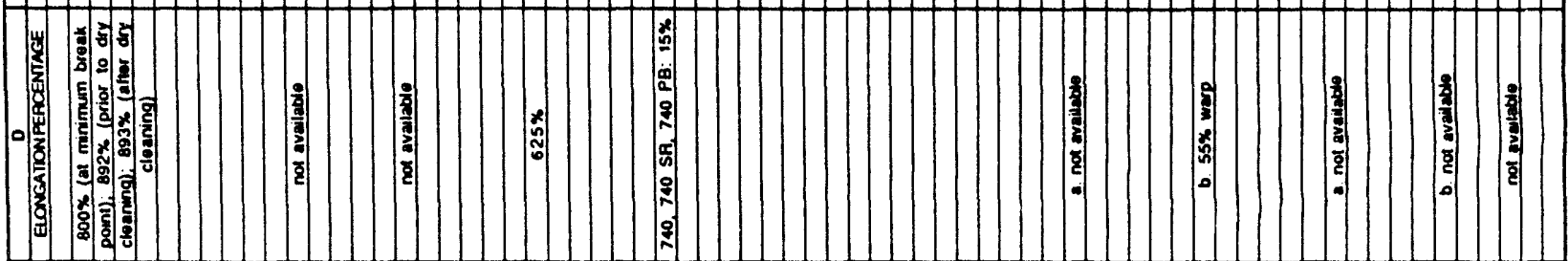

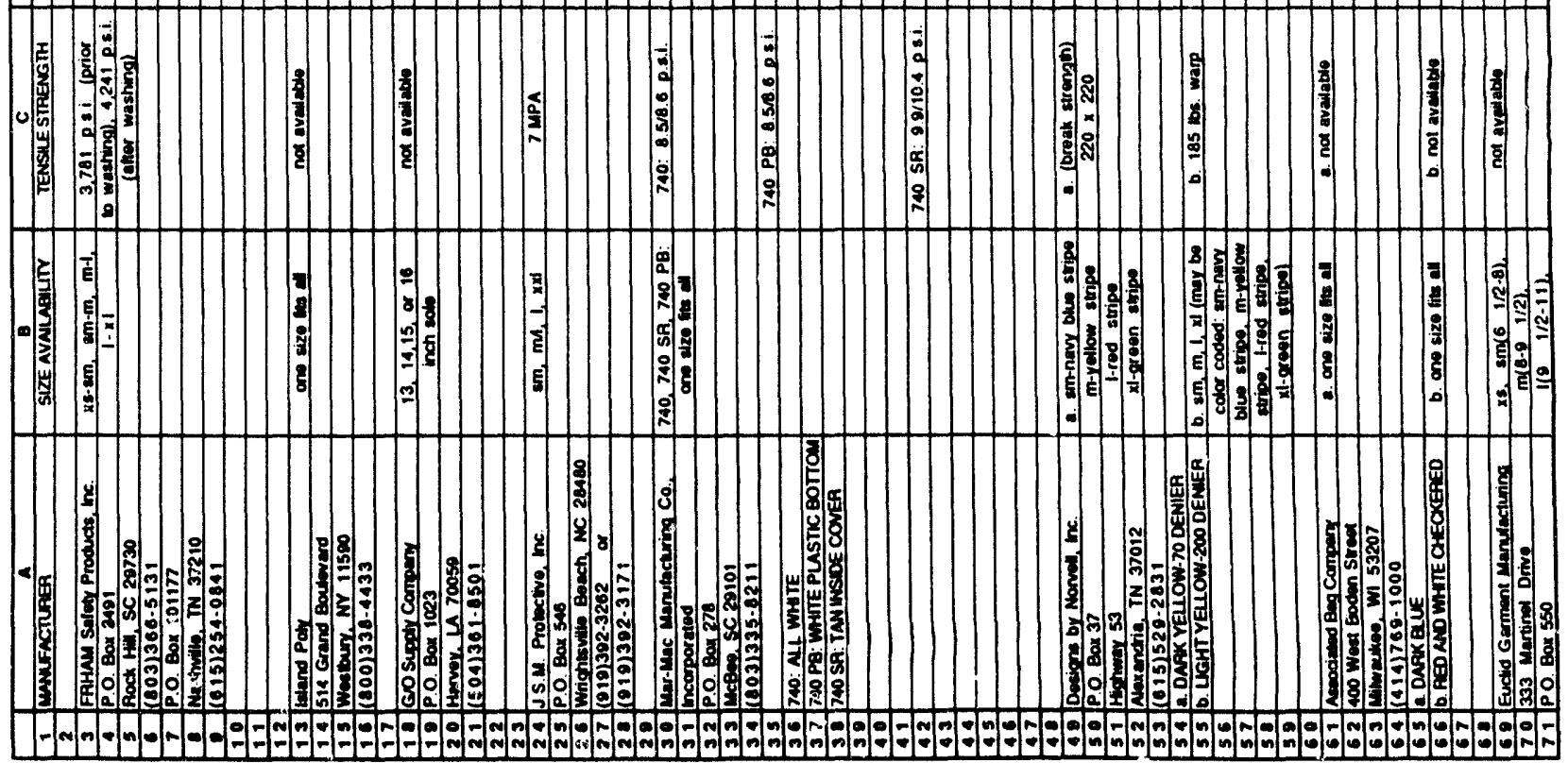




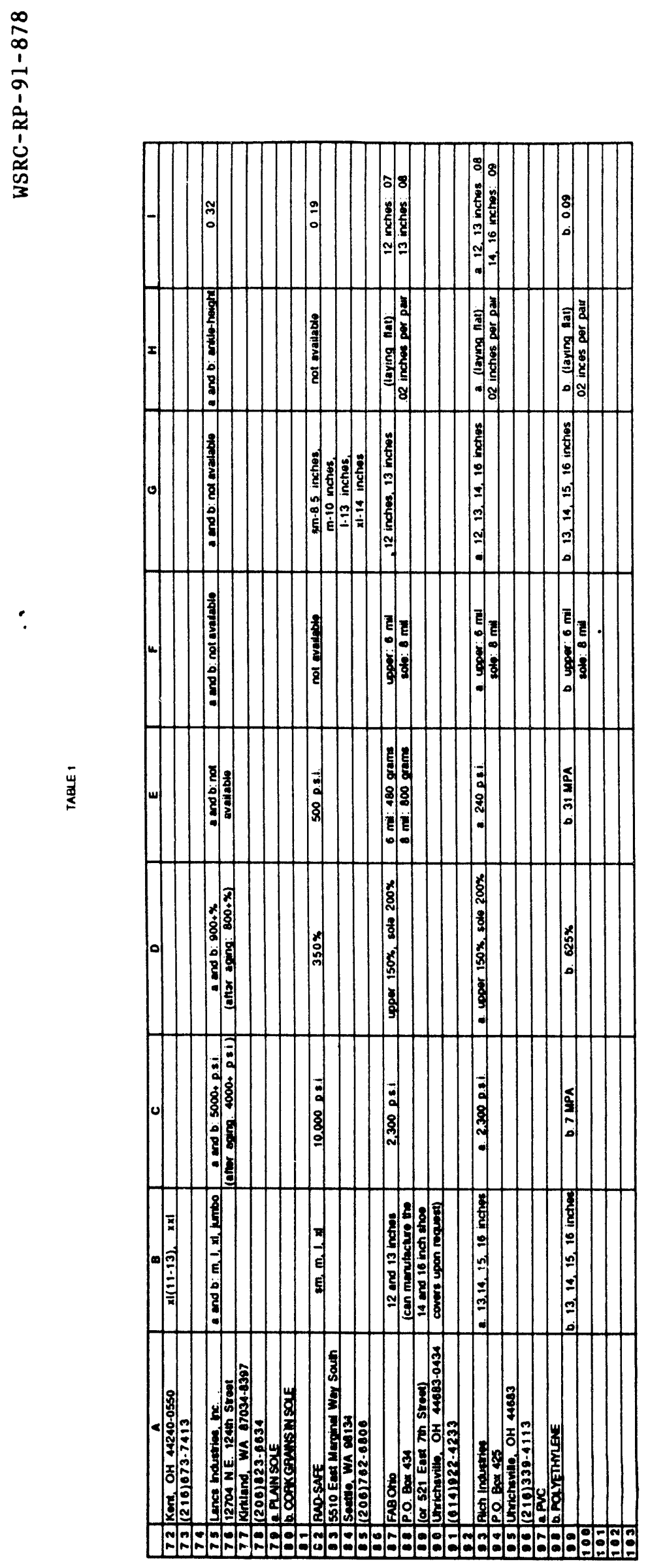




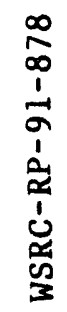

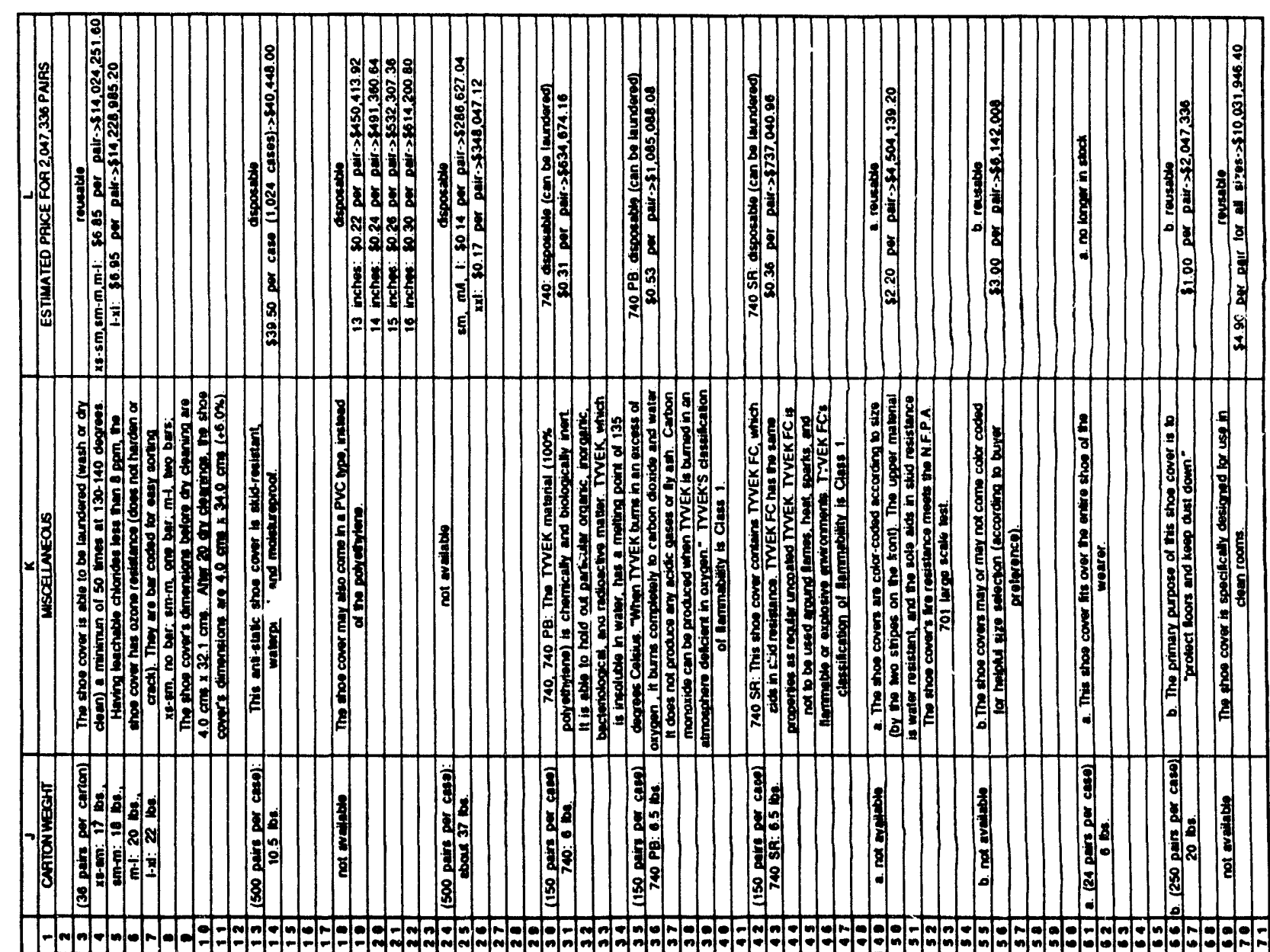

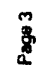


$\infty$
$\infty$
1
$a$
$\vdots$
$\vdots$
$a$
1
0
0
0
3
3

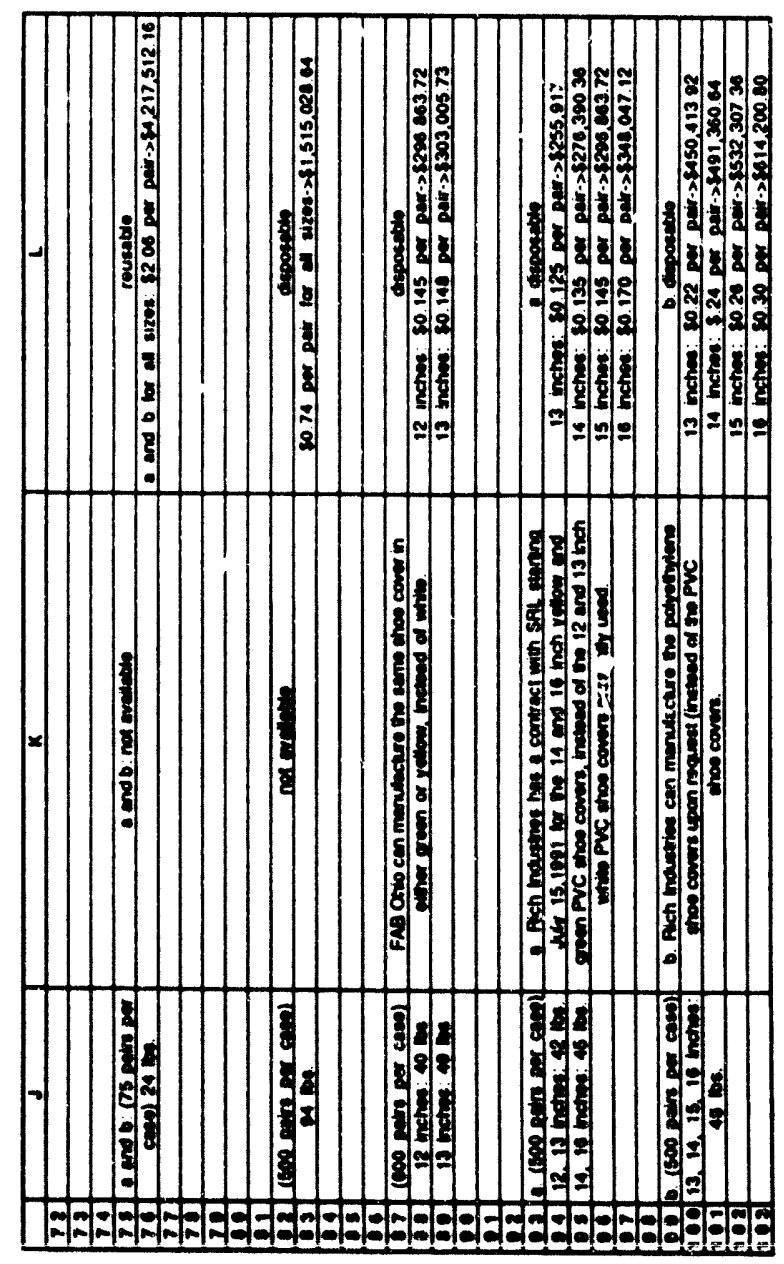




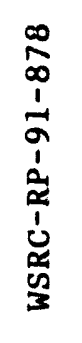

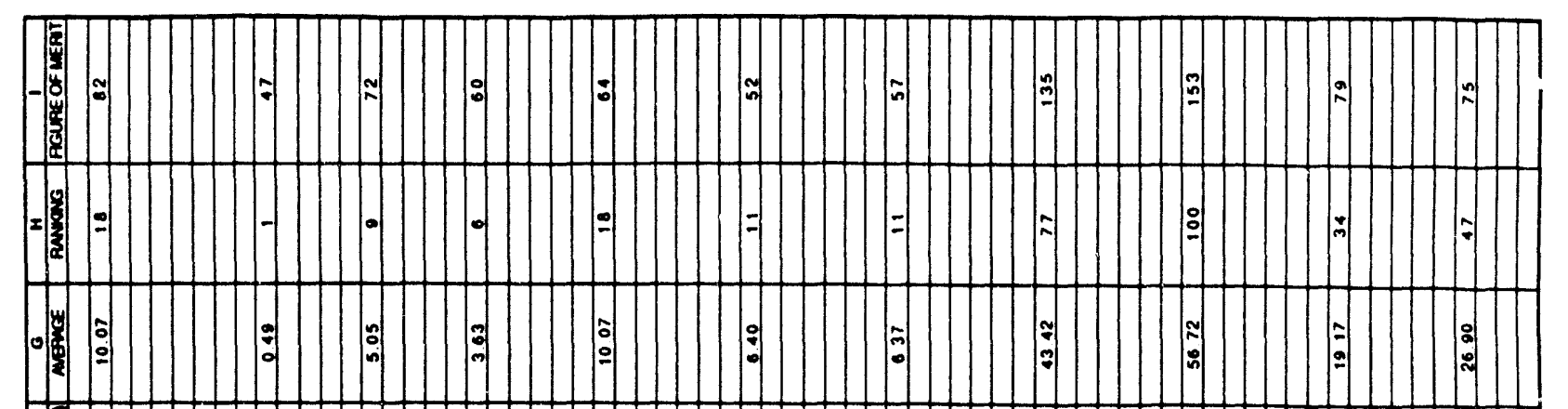

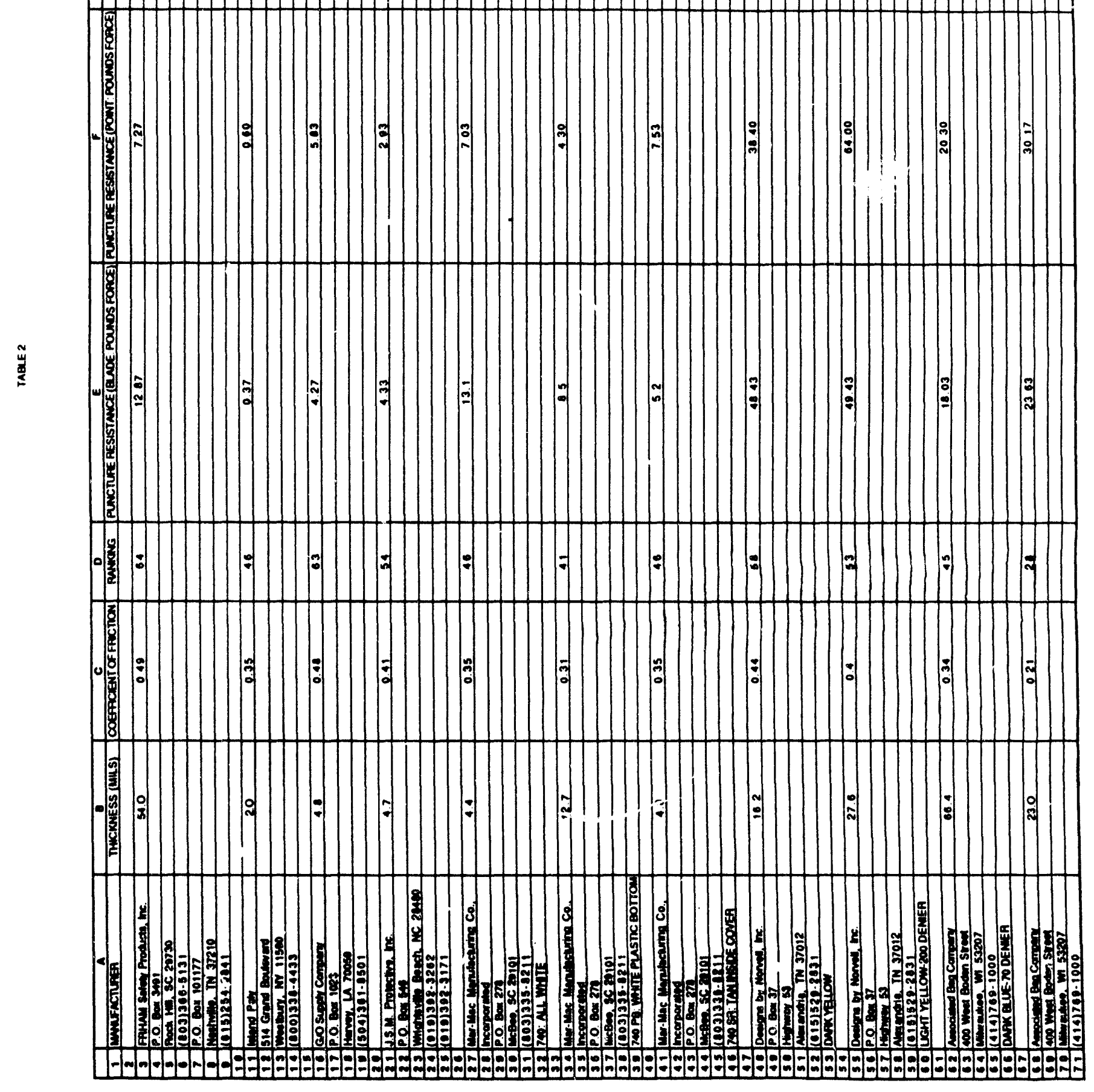




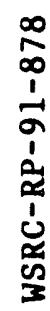

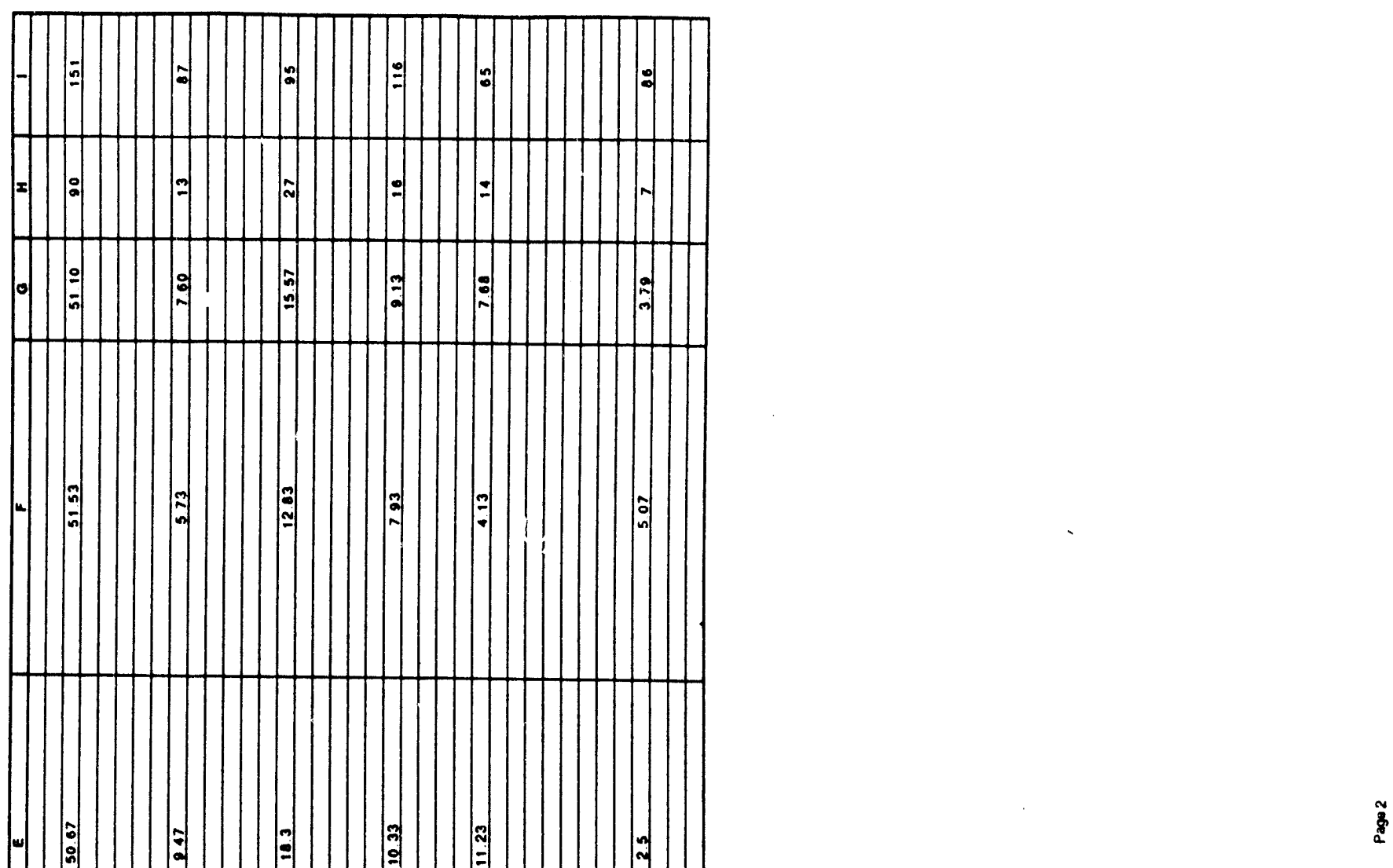




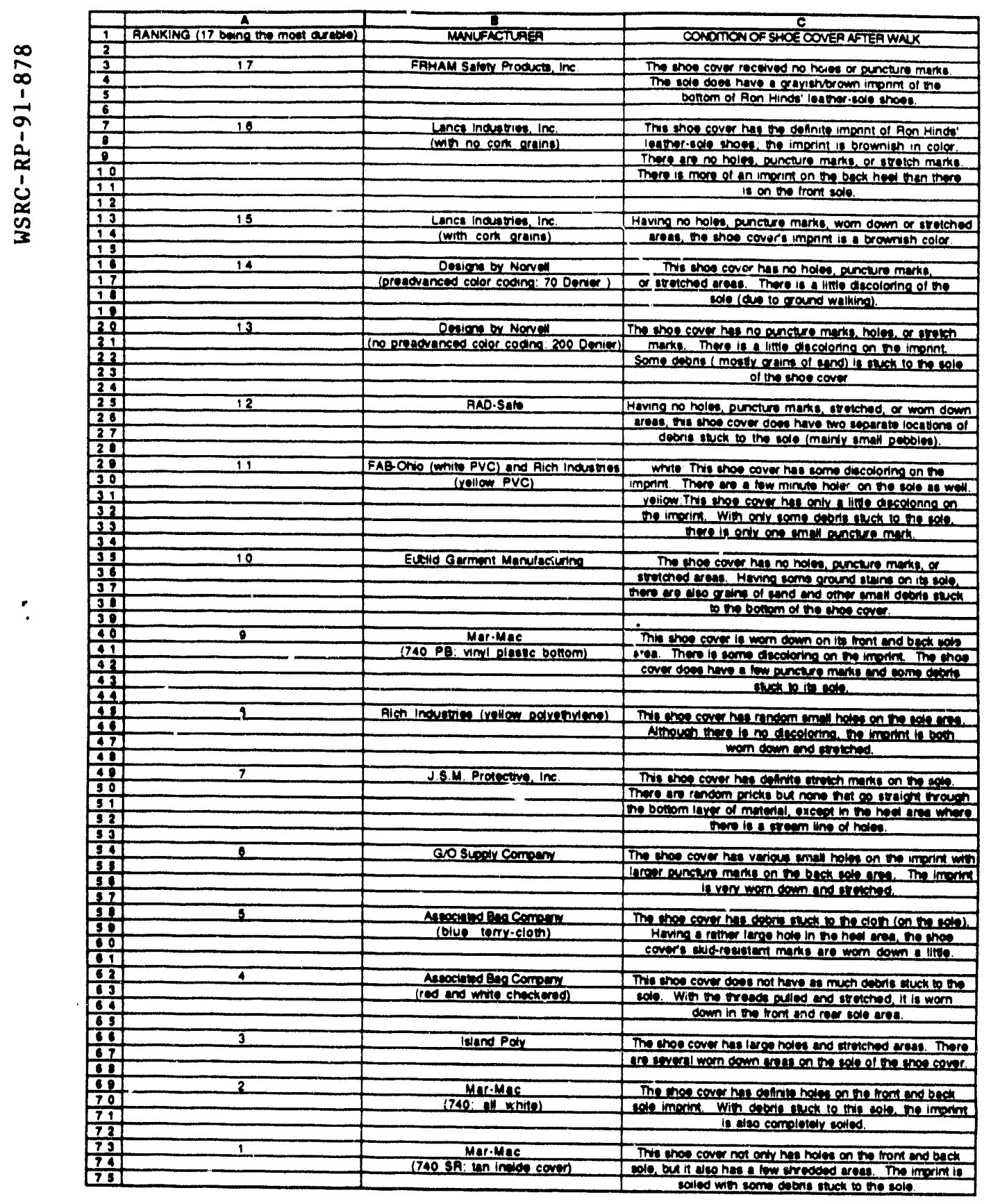




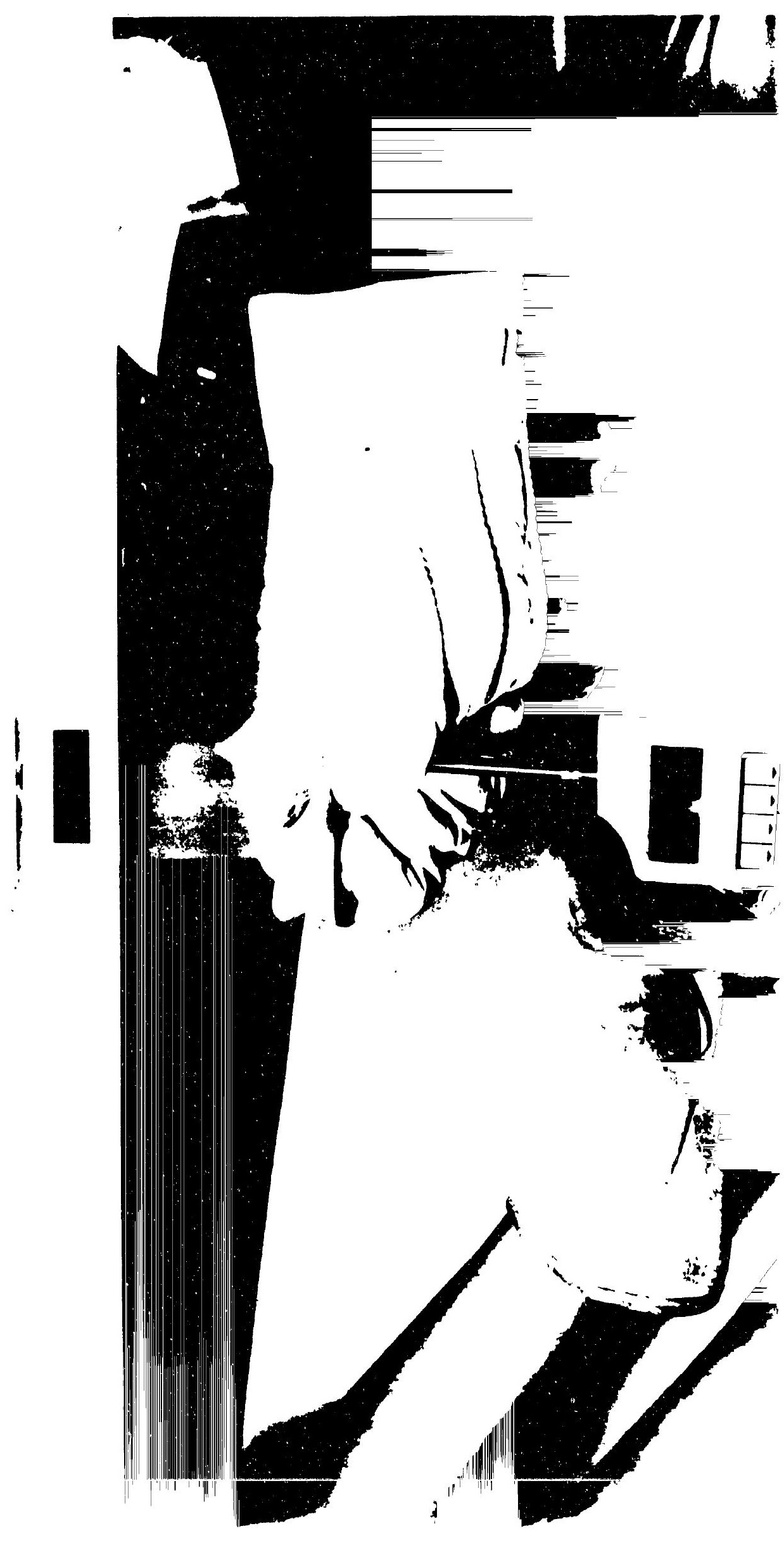




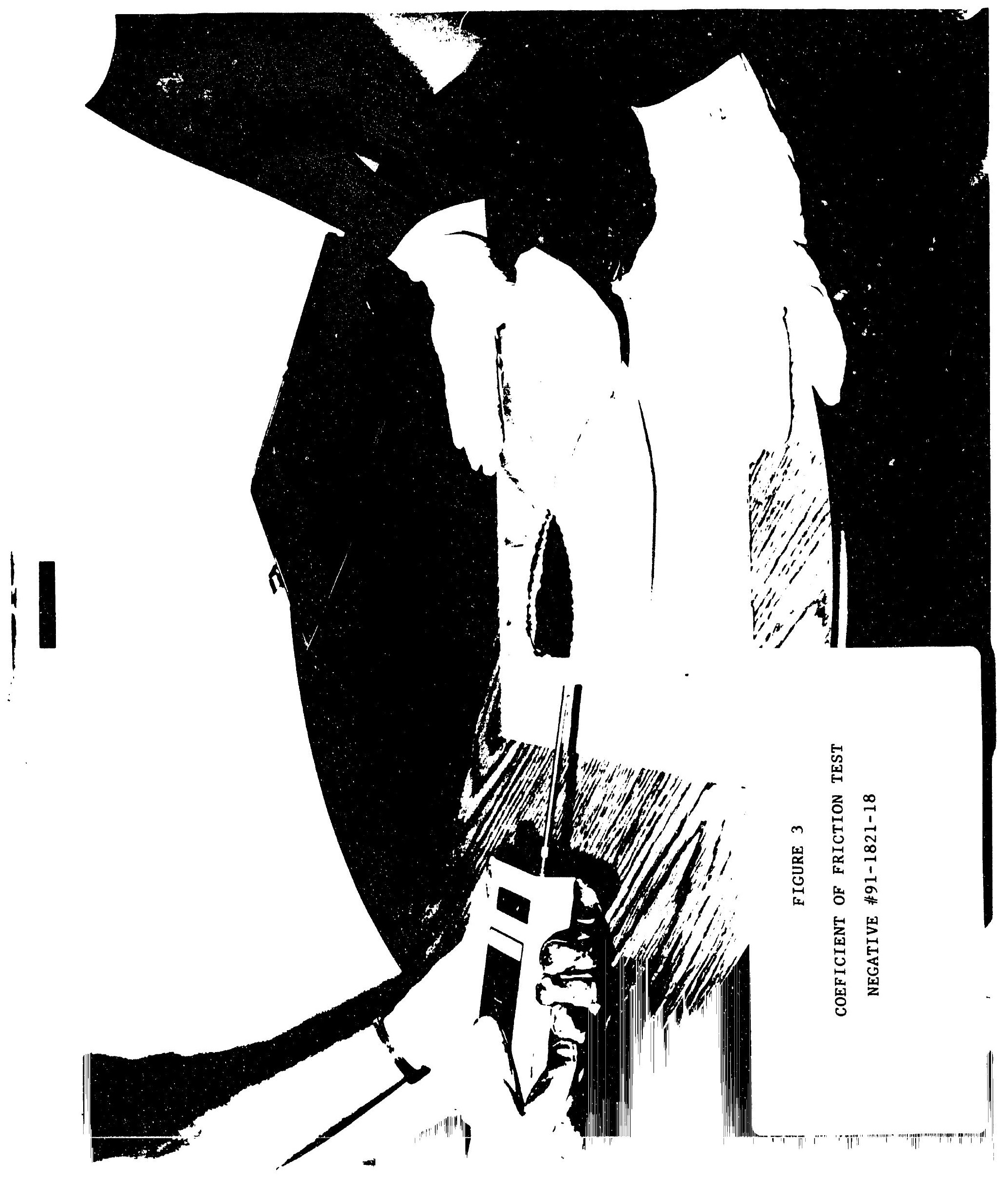




$$
I_{1}, T_{n}
$$



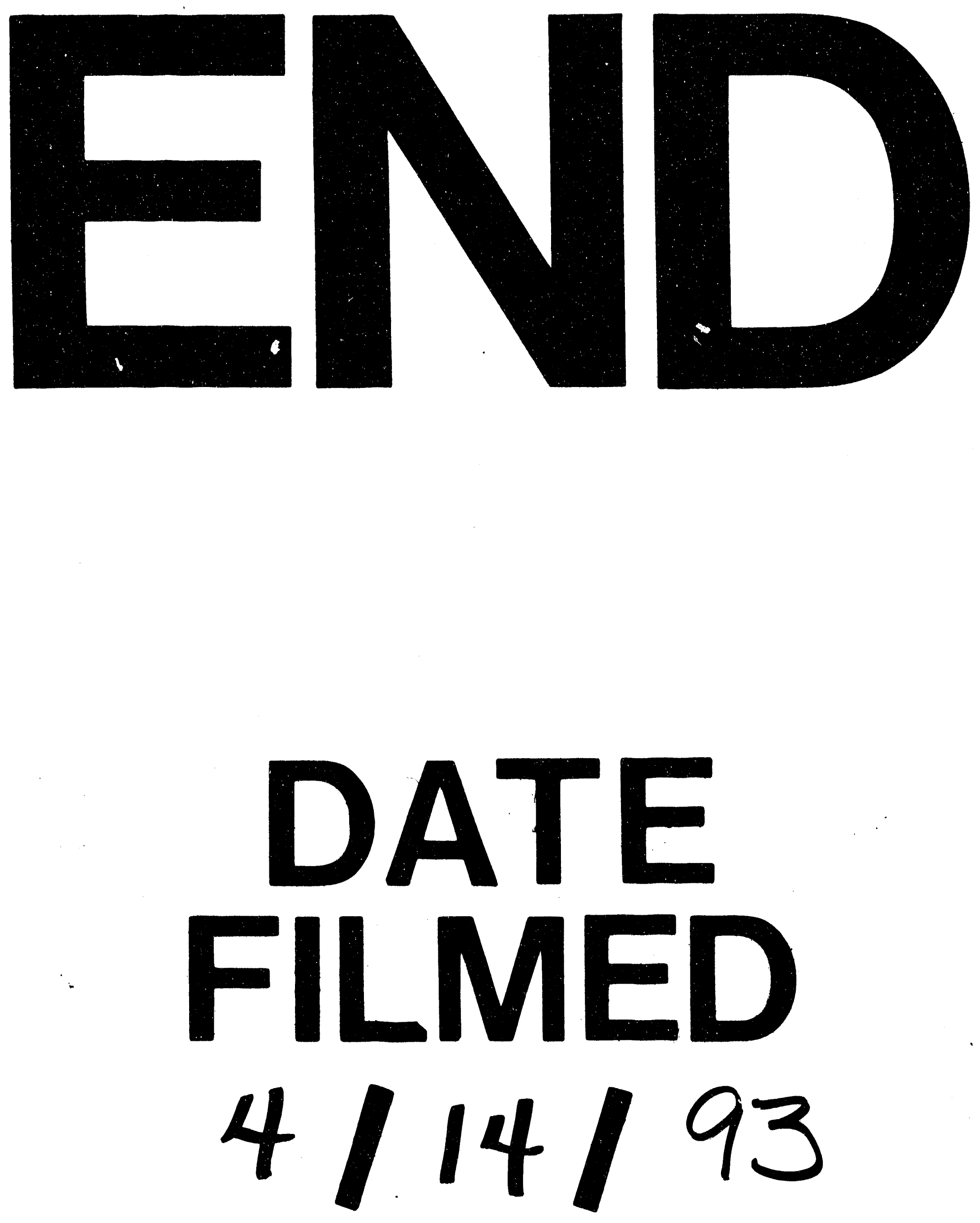

1 
